\title{
DIFERENTES GRANULOMETRIAS DO GRÃO DE MILHO SOBRE A QUANTIDADE DE AÇÚCARES EXTRAIDOS
}

\author{
S.M. MOYA; ALCANTARA, G.U.; NOGUEIRA, L.C.; COSTA, G.H.G. \\ ${ }^{1}$ Universidade Sagrado Coração de Bauru, Departamento de Engenharia Química \\ E-mail para contato: samya_moya@hotmail.com
}

\begin{abstract}
RESUMO - Atualmente, o setor sucroenergético busca novas matérias-primas que possam complementar a produção de etanol no Brasil. Entre essas, pode-se destacar o milho, que vem sendo utilizado em estados como Mato Grosso e Goiás em usinas dedicadas, ou ainda em "usinas flex", que compartilham o processamento de cana-de-açúcar e milho. Entretanto, ainda faltam informações que possam otimizar o processo, resultariam em aumento de rendimento industrial. Entre essas, cabe destacar a granulometria ideal que o grão deve apresentar antes de ser submetido ao processo de cozimento. Desta maneira, o objetivo do trabalho foi avaliar a extração dos açúcares presentes no milho triturado em diferentes granulometrias. $O$ delineamento experimental foi inteiramente casualizado com 4 tratamentos e 3 repetições. Os tratamentos foram constituídos pelas granulometrias de $0,6,1,18$ e $2,36 \mathrm{~mm}$, além de fubá (granulometria inferior a $0,6 \mathrm{~mm}$ ). $\mathrm{O}$ grão foi misturado a água destilada na proporção e $200 \mathrm{~g} / \mathrm{L}$, sendo posteriormente submetido a cozimento por 90 minutos. A seguir, foi resfriado a $80-90^{\circ} \mathrm{C}$, adicionando-se a enzima $\alpha$-amilase, mantendo a pasta em agitação por 30 minutos. A pasta foi peneirada e caracterizada quanto ao Brix, pH, Açúcares Redutores Totais (ART) e Amido. Observou-se Brix entre 14 e $18,4 \%$, Amido de 0,01 a $0,63 \%$, ART entre 11 e $17 \%$ e pH de 5,9 a 6,3. Conclui-se que a granulometria de $0,6 \mathrm{~mm}$ é a mais eficaz para extração dos açúcares do milho.
\end{abstract}

\section{INTRODUÇÃO}

O etanol atualmente é a matriz energética que mais cresce mundialmente, devido seu baixo custo de produção quando comparado às outras fontes, e principalmente por causa das questões ambientais como a busca por reduções na emissão de gases poluentes. No Brasil, a perspectiva é o aumento constante do etanol, impulsionado pelo aumento no uso de veículos automotivos leves "flex-fuel", além do incremento em mistura com a gasolina e da produção de biodiesel, que utiliza deste no processo de transesterificação (MENDONÇA, 2010; FERREIRA, 2015).

Nos últimos dez anos o setor sucroenergético no Brasil, passou por grandes transformações tanto tecnológicas quanto agrícolas, tais como: a expansão da cultura de cana para regiões diferentes das tradicionais, programas de melhoramento genético da cana-deaçúcar, substituição do corte manual pelo mecanizado com a consequente extinção da queima. Neste sentido, cabe destacar ainda as novas matérias-primas destinadas a produção de etanol, tais como o bagaço de cana hidrolisado (etanol de $2^{\mathrm{a}}$ geração), sorgo sacarino e, mais 
recentemente, o milho. Devido a esses fatores foi possível expandir o período de safra, mas ainda assim, a indústria passa por um período de entressafra onde há desabastecimento de matéria-prima (FERREIRA, 2015).

Considerando-se os grãos de milho, observa-se que esses vêm sendo utilizados para produção de etanol em estados como Mato Grosso e Goiás, que apresentam as maiores produção deste cereal no Brasil. O milho é uma planta anual que poder ser cultivada tanto no verão, quanto no outono/inverno (milho safrinha). Mas com uma logística inadequada para transporte do milho até o mercado consumidor e com níveis de tecnologia que permitem a produção com menor custo, os produtores enxergam vantagem no desenvolvimento de Usinas Flex, que seria a utilização do milho no período de entressafra da cana-de-açúcar. E outros procuram investir em usinas que só utilizam o milho por ser uma planta anual (DONKE, 2016).

Embora a produção de etanol a partir do milho seja realidade no Brasil, ainda faltam informações que possam otimizar a extração do amido do grão, resultando em aumento dos rendimentos industriais. Entre essas, cabe destacar a granulometria ideal que o milho deve apresentar ao ser submetido a processo de cozimento para extração dos açúcares. Desta maneira, o objetivo do trabalho foi avaliar a extração dos açúcares presentes no milho triturado em diferentes granulometrias.

\section{MATERIAL E MÉTODOS}

O experimento foi realizado no Laboratório de Biomassa e Bioenergia da Universidade do Sagrado Coração de Bauru-SP, no segundo semestre de 2016. Os milhos e o fubá foram obtidos em unidades comerciais da região de Bauru.

Os grãos de milho foram triturados até as granulometrias de $0,6,1,18$ e 2,36mm, utilizando-se triturador com potência de $1,5 \mathrm{cv}-60 \mathrm{~Hz}$, e posteriormente com auxílio de um sistema de peneiras de $187 \mathrm{~W}-50 / 60 \mathrm{~Hz}$ foram classificados. Esses, assim como o fubá, foram misturados com água na proporção de $200 \mathrm{~g} / \mathrm{L}$ e submetidos a processo de cozimento por 90 minutos. A seguir, foram resfriados a $80-90^{\circ} \mathrm{C}$, adicionando-se a enzima $\alpha$-amilase (300 KNU/g), mantendo a pasta em agitação por 30 minutos. A pastas foram peneiradas e caracterizadas quanto ao Brix, pH (CTC, 2005), Açúcares Redutores Totais (MILLER, 1959) e Amido (CHAVAN et al., 1991).

O delineamento experimental foi inteiramente casualizado, com 4 tratamentos (fubá, milho com granulometria de 0,6,1,18 e 2,36mm) e 3 repetições. Os resultados foram submetidos a análise de variância pelo teste $\mathrm{F}$, e as médias comparadas segundo teste de Tukey (5\%). 


\section{RESULTADOS E DISCUSSÃO}

Na tabela 1 estão apresentados os valores obtidos para Brix, Açúcares Redutores Totais (ART), Amido e pH dos grãos de milho em diferente granulometrias.

Considerando-se o Brix, observou-se que o fubá apresentou os menores valores, enquanto as demais granulometrias apresentaram variações semelhantes de 17 a $18^{\circ}$ Brix. Avaliando-se o ART, verificou-se que o menor valor foi obtido a partir da utilização do fubá, enquanto o uso de grão de $0,6 \mathrm{~mm}$ resultou na extração de $6 \%$ a mais de açúcares. Estes valores foram similares aos obtidos por Masson et al. (2015), que observaram que o caldo da cana-de-açúcar e do sorgo sacarino apresentam ART entre 15 e 17\%. Desta maneira, cabe inferir que a utilização de milho triturado a $0,6 \mathrm{~mm}$, resulta em matéria-prima similar a utilizada atualmente pelo setor sucroenergético.

Analisando-se o teor de amido das pastas, verificou-se que quanto maior a granulometria utilizada, maior é a sobra de amido. Este fato pode ser decorrente da maior barreira física presente nessas condições, que impedem o contato da enzima com o amido, impedindo a hidrólise. $\mathrm{O} \mathrm{pH}$ das pastas variaram de 5,9 a 6,3. Nessas condições, deve-se realizar prévia acidificação do meio até $\mathrm{pH} 4,5$, objetivando a adequação das condições do substrato para a levedura fermentar (BASSO et al., 2011).

Tabela 1 - Valores médios obtidos para Brix, Açúcares Redutores Totais (ART), Amido e pH das pastas preparadas a partir de milhos em diferentes granulometrias

\begin{tabular}{|c|c|c|c|c|}
\hline Tratamentos & $\begin{array}{c}\text { Brix } \\
\%\end{array}$ & $\begin{array}{c}\text { ART } \\
\%\end{array}$ & $\begin{array}{c}\text { Amido } \\
\%\end{array}$ & $\mathrm{pH}$ \\
\hline Fubá & $14,0 \mathrm{~B}$ & $11,70 \mathrm{C}$ & $0,01 \mathrm{D}$ & $6,3 \mathrm{~A}$ \\
$0,6 \mathrm{~mm}$ & $17,7 \mathrm{~A}$ & $17,18 \mathrm{~A}$ & $0,14 \mathrm{C}$ & $6,1 \mathrm{~B}$ \\
$1,18 \mathrm{~mm}$ & $18,4 \mathrm{~A}$ & $13,76 \mathrm{~B}$ & $0,40 \mathrm{~B}$ & $5,9 \mathrm{C}$ \\
$2,36 \mathrm{~mm}$ & $17,6 \mathrm{~A}$ & $14,09 \mathrm{~B}$ & $0,63 \mathrm{~A}$ & $6,0 \mathrm{BC}$ \\
\hline Teste F & $19,66^{* *}$ & $35,27^{* *}$ & $113,90^{* *}$ & $59,16^{* *}$ \\
DMS & 2,04 & 1,72 & 0,11 & 0,10 \\
CV $(\%)$ & 4,62 & 4,65 & 14,68 & 0,67 \\
\hline
\end{tabular}

Letras diferentes na mesma coluna indicam diferença significativa segundo o teste de Tukey $(5 \%)$. **significativo ao nível de $1 \%$ de probabilidade. DMS - Desvio Mínimo Significativo. CV - Coeficiente de Variação

\section{CONCLUSÃO}

A utilização de grão de milho a granulometria de $0,6 \mathrm{~mm}$ resulta em maiores teores de açúcares extraídos. 


\section{REFERÊNCIAS}

BASSO, L. C.; ROCHA, S. N.; BASSO, T. O. Ethanol production in Brazil: the industrial process and its impact on yeast fermentation. Biofuel Production-Recent Developments and Prospects. Dr Marco Aurelio dos Santos Bernardes (ed.), ISBN: 97-953-307-478-8, INTECH, 2011. Disponível em: <http://cdn.intechopen.com/pdfs/20058.pdf $>$. Acesso em: 01 nov. 2016.

CHAVAN, S. M.; KUMAR, A.; JADHAV, S. J. Rapid quantitative analysis of starch in sugarcane juice. International Sugar Journal, Glamorgan, v. 93, n. 107, 1991.

CTC - Centro de Tecnologia Canavieira. Manual de métodos de análises para açúcar. Piracicaba, Centro de Tecnologia Canavieira, Laboratório de análises, 2005. Disponível em CD ROM.

DONKE, A. C. G. A produção de etanol pela integração do milho-safrinha às usinas de canade-açúcar: avaliação ambiental, econômica e sugestões de política. São Paulo: Revista do BNDES, 2016.

FERREIRA, O. E. Produção de etanol a partir de sorgo sacarino com tratamento enzimático. Universidade Estadual Paulista, Faculdade de Ciências Agrárias e Veterinárias. Jabuticabal, 2015.

MASSON, I.S.; COSTA, G.H.G; ROVIERO, J.P.; FREITA, L.A.; MUTTON, M.A.; MUTTON, M.J.R. Produção de bioetanol a partir da fermentação de caldo de sorgo sacarino e cana-de-açúcar. Ciência Rural, v.45, n.9, 2015.

MENDONÇA, J. F. Comparação dos custos de produção e logísticos de etanol entre Brasil e Estados Unidos. Volta Redonda, 2010.

MILLER, G.L. Use of de dinitrosalicylic acid reagent for determination of reducing sugar. Analytical Chemistry, v.31, n.3, 1959. 